\title{
Correction: Adverse effect of excess body weight on survival in cervical cancer patients after surgery and radiotherapy
}

\author{
Yunseon Choi, MD, PhD'1, Ki Jung Ahn, MD, PhD¹, Sung Kwang Park, PhD', \\ Heunglae Cho, MD, PhD', Ji Young Lee, MD² \\ ${ }^{1}$ Department of Radiation Oncology, ${ }^{2}$ Division of Oncology/Hematology, Department of Internal Medicine, Inje University Busan \\ Paik Hospital, Inje University College of Medicine, Busan, Korea
}

https://doi.org/10.3857/roj.2016.01977

Radiat Oncol J 2017;35(1):48-54

We noticed that the original version of this paper contains typographical error in Fig. 2.

In Fig. 2 (page 52), 'BMI $\geq 23 \mathrm{~kg} / \mathrm{m}^{2}(\mathrm{n}=36)$ ' must be changed into 'BMI $<23 \mathrm{~kg} / \mathrm{m}^{2}(\mathrm{n}=36)$ '.

Corrected version of the figure appear below.

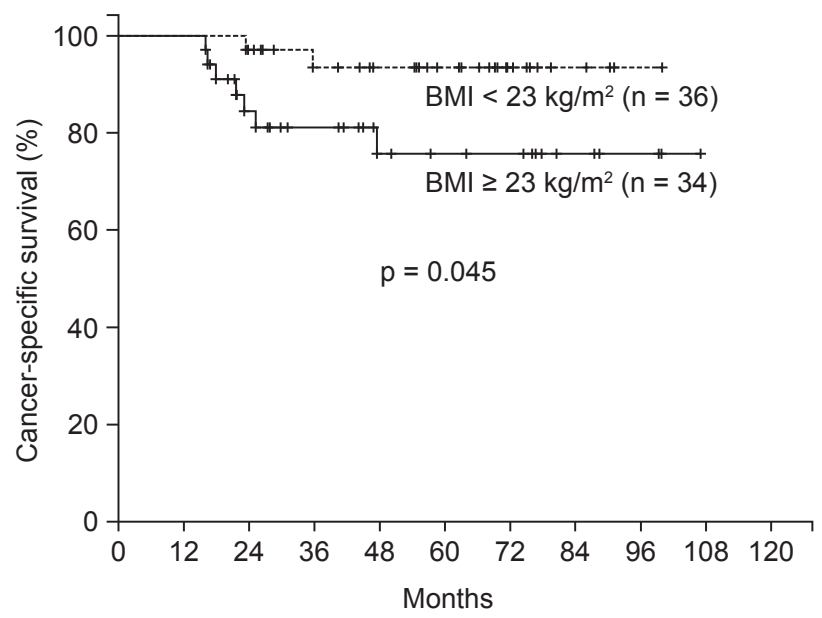

Fig. 2. Cancer-specific survival by overweight or obesity.

(c) This is an Open Access article distributed under the terms of the Creative Commons Attribution Non-Commercial License (http://creativecommons.org/ licenses/by-nc/4.0/) which permits unrestricted non-commercial use, distribution, and reproduction in any medium, provided the original work is properly cited.

www.e-roj.org 